\title{
Numerical Study and Comparison of the Settlement Behaviours of Axially Loaded Piles using Different Material Models
}

\author{
S. Gowthaman, M.C.M. Nasvi and S. Krishnya
}

\begin{abstract}
The settlement behaviour of axially loaded piles is one of the prime factors that control the design of single and group piles. Therefore, this research focused on the settlement behaviour of a pile foundation located in sandy-silt under the load of a high-rise building, by simulating it using PLAXIS numerical package and giving consideration to interface effects. Four different types of analysis were investigated: (i) a Linear Elastic (LE) analysis where the soil was assumed as linear-elastic; (ii) a simple Non Linear (NL) analysis where the soil was completely assumed as a Mohr-Coulomb(MC) model; (iii) Non Linear (NL) analysis where the soil was completely assumed as a Hardening -Soil (HS) model; and (iv) a combined (NL-LE and NL-NL) analysis assuming that the soil close to the pile shaft is a nonlinear model and that the soil in the remaining area is made of either linear material or simple nonlinear material (MC). The results of the analysis suggest that the complete MC model shows good agreement with the settlement behaviour obtained from field static load tests at lower working loads. However, the incorporation of a nonlinear HS interface zone of soil is required to predict the settlement at higher working loads. In addition, it was noted that an interface thickness that is twice the pile diameter with the remaining soil modelled as MC would suffice to ascertain the load transfer mechanism of a typical pile.
\end{abstract}

Keywords: Hardening-soil model, Interface, Linear-elastic, Mohr-coulomb model, Settlement.

\section{Introduction}

Presently, there are many high rise buildings and transportation structures such as highways and bridges being constructed on pile foundations. The demand on axially loaded piles is increasing daily because of their high bearing capacity and their applicability in various types of geological strata. The settlement of the pile foundation is a controlling factor of its design because the primary purpose of the pile foundation is to limit the deformation of the structure it supports $[1,2,3]$.

In the past, there have been various techniques such as experimental techniques, analytical techniques and numerical techniques which have been adopted by researchers to predict the actual settlement behaviour of pile foundations. Based on the outcomes of this research, a number of approximate solutions have been provided for different conditions. McCabe and Lehane [4] have conducted an experimental field study on the settlement behaviour of axially loaded driven piles in soft clay-silt. Horikoshi et al. [5] have also done a laboratory based study on the settlement behaviour of piles. The rational analyses of pile group displacements had been pioneered by Poulos [6] who introduced the concept of 'interaction factors' for pile groups. After carrying out several field tests, Sonia and Desai [7] have proposed useful values for the ultimate point resistance and skin resistance based on the type of piles installed in cohesion less soil. Randolph and Wroth [8] have proposed a useful empirical equation for the settlement of pile foundations. Randolph [9] has proposed a simplified analytical approach (RATZ approach) to predict the behaviour of group piles. He has used a parabolic or hyperbolic curve to describe the behaviour of an individual pile. However, the related formulae have not been able to fit and predict the entire process of "settlementload" curves $[3,10]$. Therefore, the prediction of the settlement of a pile foundation has to be based on a numerical method.

Nowadays, the numerical simulation of structures is one of the most popular approaches widely used in geotechnical and structural analysis [11].

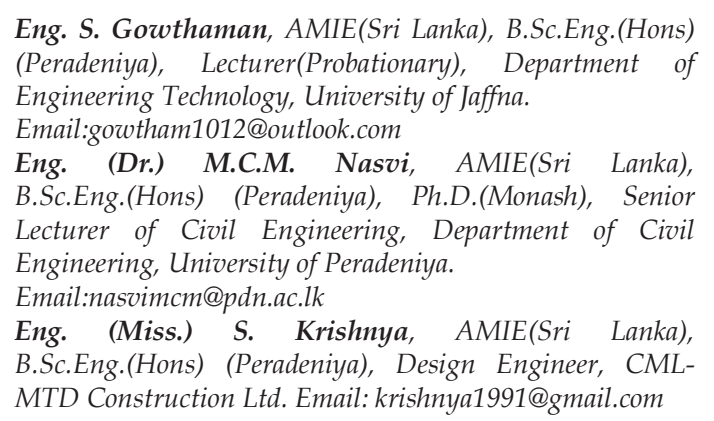


Numerical analysis provides immediate and suitable solutions for various field problems which can be used for similar type of field problems that arise in the future as well. During the past few years, there has been an obvious trend towards developing finite element techniques as they give very reliabile and accurate solutions to complex engineering problems. Zakia et al. [11] using PLAXIS 2D have conducted a finite element study on the effect of modelling parameters on settlement predictions. It has been found that the (i) modulus of interface is very much closer to the modulus of the soil that is in contact with the pile (ii) interface reduction factor provides good agreement when its value is between 0.8 and 0.9 (iii) modelling the soil completely using a Mohr Coulomb model giving consideration to the interface provides a better settlement prediction and (iv) fine mesh provides more reliable agreement compared to coarse mesh. Jun Ju [12] has carried out settlement analysis using the finite element approach of PLAXIS 3D for piles in sleech soil. Based on the findings, it has been concluded that a combination of nonlinear and linear elastic analysis leads to more realistic predictions of settlement than a complete nonlinear analysis of soil. Jian-lin et al. [3] have conducted a study on the settlement prediction of pile foundations in deep clayey soil deposits using Finite Element Modelling. They have proposed a useful equation to correct the compression modulus obtained from laboratory tests and it has been suggested to use it in numerical simulations of deep soft soil. Alnuiam et al. [13] have developed a Finite Element Model (FEM) using the PLAXIS 3D package to study the settlement behaviour of piles in Toyoura sand and have proposed that the Mohr Coulomb (MC) model is the best model to predict the settlement behaviour of piles in Toyoura sand.

However, the reliable prediction of the settlement of pile foundations at typical working loads remains one of the major geotechnical engineering problems [4, 12]. To date, there have been only a very limited number of analyses performed using finite element techniques. As such, it is very essential to analyse the settlement behaviour of axially loaded piles to ensure a safe and economical design.

Therefore, this research study through the use of finite element techniques, primarily focused on the numerical simulation of the settlement behaviour of vertically loaded piles used to transfer the load from a super structure to geo strata.

\section{Pile Case History}

In this research study, the pile load test result of the north western part of Singapore (Woodland) was used. Old Alluvium is one of the major formations of the geological stratigraphy of Singapore and covers about 15\% of the total area of that country [14]. It consists of sand, silt, and clay that had predominantly silty sand with a fine content of about $20 \%$ to $30 \%$ [14]. A site investigation including standard penetration tests was carried out to obtain the required engineering information as well as the description of subsurface soil and the basic structure of the stratigraphy. The water table was found to be at a depth of $1 \mathrm{~m}$ below the ground surface. The basic subsurface soil parameters of multi layered soil already investigated into and proposed by Li et al. [15] with respect to the depth are summarized in Table 1.

The single reference pile used at this site was a precast circular concrete pile, $48 \mathrm{~m}$ long and $1500 \mathrm{~mm}$ in diameter, driven to a depth of 47.5 $\mathrm{m}$ in the ground with a free-standing length of $0.5 \mathrm{~m}$ above the ground. The additional properties of the reference pile are its unit weight of $24 \mathrm{kN} / \mathrm{m}^{3}$, elastic modulus of $30 \mathrm{GPa}$ and Poisson's ratio of 0.2. Static load test was performed on the reference pile up to $21,000 \mathrm{kN}$ (300\% of the working load) three months after its installation.

\section{Soil Models and Properties}

\subsection{Linear Elastic (LE) Model}

This numerical simulation of the pile load test was performed using the Finite Element Program PLAXIS 2D. The very basic LE model which is one of the models available with the PLAXIS package was adopted to perform linear elastic analysis on the material used in this research study. The Linear Elastic model is based on Hookes's Law of isotropic elasticity. It involves two basic elastic parameters, i.e., Young's modulus (E) and Poisson's ratio $\left(\mathrm{v}_{\mathrm{s}}\right)$. Although the linear elastic model is not suitable to model the soil, it may be used to model the stiff volumes of soil or stiff formations in the soil [16].

\subsection{Mohr Coulomb Model}

Mohr Coulomb (MC) model is one of the nonlinear models adopted in this research study. The MC model is a simple nonlinear model which is based on soil parameters that 
are known in most of the practical situations. It involves five input parameters, i.e. Elastic modulus (E) and Poisson's ratio $\left(\mathrm{v}_{\mathrm{s}}\right)$ for soil elasticity, friction angle $(\varphi)$ and cohesion (c) for soil plasticity and dilatancy angle $(\Psi)$. However, the model does not contain all of the non-linear features of soil behaviour.

The LE and MC model parameters for Old Alluvium are summarized in Table 2. Orihara and Khoo [14] have conducted a number of
Standard Penetration Tests (SPTs) and Consolidated Drained (CD) triaxial tests for the layers using piston samples that were consolidated isotropically to a stress of $100 \mathrm{kPa}$ $\left(\sigma_{3}\right)$. Based on the results of their experiments, they have correlated the strength parameters (c and $\Phi$ ) of Old Alluvium with SPT values (N). In this research study, the correlations proposed by Orihara and Khoo [14] were used to derive c and $\Phi$ of Old Alluvium from the SPT values.

Table 1 - Sub surface soil stratigraphy of the site (After Li et al. [15])

\begin{tabular}{c|cccccc}
\hline $\begin{array}{c}\text { No. of } \\
\text { layers }\end{array}$ & Depth $(\mathrm{m})$ & Soil description & $\begin{array}{c}\text { Moisture } \\
\text { content } \\
(\%)\end{array}$ & $\begin{array}{c}\text { Bulk } \\
\text { density } \\
\left(\mathrm{kN} / \mathrm{m}^{3}\right)\end{array}$ & $\begin{array}{c}\text { Dry } \\
\text { density } \\
\left(\mathrm{kN} / \mathrm{m}^{3}\right)\end{array}$ & $\begin{array}{c}k\left(\times \mathbf{1 0}^{-8}\right. \\
\mathrm{m} / \mathrm{s})\end{array}$ \\
\hline 1 & $0-2.4$ & Silty sand & 22 & 20.3 & 16.6 & 18.8 \\
2 & $2.4-5.4$ & Silty sand & 22 & 20.3 & 16.6 & 18.8 \\
3 & $5.4-8.4$ & Medium dense silty sand & 22 & 20.3 & 16.6 & 18.8 \\
4 & $8.4-14.4$ & Medium dense silty sand & 18.2 & 20.7 & 17.6 & 6.4 \\
5 & $14.4-26.4$ & Medium dense silty sand & 16.3 & 20.3 & 17.6 & 3.8 \\
6 & $26.4-41.4$ & Dense silty sand & 16.3 & 20.3 & 17.6 & 3.8 \\
7 & $41.4-44.4$ & Very dense silty sand & 16.3 & 20.3 & 17.8 & 3.8 \\
8 & $44.4-47.4$ & Very dense silty sand & 16.3 & 20.3 & 17.8 & 3.8 \\
9 & Below 47.4 & Very dense silty sand & 16.3 & 20.3 & 17.8 & 3.8 \\
\hline
\end{tabular}

Table 2 - Parameters used for LE and MC model (After Orihara and Khoo [14])

\begin{tabular}{c|ccccccc}
\hline $\begin{array}{c}\text { No. of } \\
\text { layers }\end{array}$ & Depth $(\boldsymbol{m})$ & $\begin{array}{c}\text { Corrected } \\
\text { Avg. } S P T \\
\text { values }\end{array}$ & $\begin{array}{c}\boldsymbol{c}^{\prime} \\
\left(\boldsymbol{k N} / \mathbf{m}^{2}\right)\end{array}$ & $\boldsymbol{\Phi}^{\prime}{ }^{\square}$ & $\begin{array}{c}\text { Elastics } \\
\text { modulus } \\
(\mathbf{M P a})\end{array}$ & $\begin{array}{c}\text { Poisson's } \\
\text { ratio }\left(\boldsymbol{v}_{\mathbf{s}}\right)\end{array}$ & $\begin{array}{c}\text { Dilatancy } \\
\text { angle }(\boldsymbol{\Psi}) /\end{array}$ \\
\hline 1 & $0-2.4$ & 10 & 5 & 32 & 21 & 0.3 & 5 \\
2 & $2.4-5.4$ & 12 & 10 & 34 & 22 & 0.3 & 5 \\
3 & $5.4-8.4$ & 16 & 10 & 34 & 28 & 0.3 & 5 \\
4 & $8.4-14.4$ & 16 & 10 & 34 & 28 & 0.3 & 5 \\
5 & $14.4-26.4$ & 25 & 10 & 34 & 42 & 0.3 & 4 \\
6 & $26.4-41.4$ & 35 & 15 & 34 & 56 & 0.3 & 3 \\
7 & $41.4-44.4$ & 45 & 15 & 34 & 70 & 0.3 & 2 \\
8 & $44.4-47.4$ & 40 & 15 & 34 & 63 & 0.3 & 2 \\
9 & Below 47.4 & 40 & 15 & 34 & 63 & 0.3 & 2 \\
\hline
\end{tabular}

Table 3 - Soil parameters for HS model (After Jun Ju, 2013)

\begin{tabular}{c|cccccccc}
\hline $\begin{array}{l}\text { No. of } \\
\text { layers }\end{array}$ & Depth $(m)$ & $E_{50}(\mathbf{M P a})$ & $E_{\text {oed }}(\mathbf{M P a})$ & $E_{\text {ur }}(\mathbf{M P a})$ & $p^{\text {ref }}(k N)$ & $m$ & $v_{u r}$ & $R_{f}$ \\
\hline 1 & $0-2.4$ & 15.6 & 15.6 & 46.8 & 100 & 0.7 & 0.2 & 0.9 \\
2 & $2.4-5.4$ & 16.3 & 15.6 & 49.0 & 100 & 0.7 & 0.2 & 0.9 \\
3 & $5.4-8.4$ & 20.8 & 20.8 & 62.4 & 100 & 0.7 & 0.2 & 0.9 \\
4 & $8.4-14.4$ & 20.8 & 20.8 & 62.4 & 100 & 0.7 & 0.2 & 0.9 \\
5 & $14.4-26.4$ & 31.2 & 31.2 & 93.6 & 100 & 0.7 & 0.2 & 0.9 \\
6 & $26.4-41.4$ & 41.6 & 41.6 & 124.8 & 100 & 0.7 & 0.2 & 0.9 \\
7 & $41.4-44.4$ & 52 & 52 & 156 & 100 & 0.7 & 0.2 & 0.9 \\
8 & $44.4-47.4$ & 46.8 & 46.8 & 140.4 & 100 & 0.7 & 0.2 & 0.9 \\
9 & Below 47.4 & 46.8 & 46.8 & 140.4 & 100 & 0.7 & 0.2 & 0.9 \\
\hline
\end{tabular}




\subsection{Hardening Soil (HS) Model}

Hardening Soil model is an advanced nonlinear model adopted for the simulation of soil behaviour. Schanz et al. [17] and Jun Ju [12] have described the Hardening Soil model (HS) in detail formulating it in the framework of classical theory of plasticity. Total strains are calculated using a stress level dependent stiffness with a hyperbolic stress-strain relationship that is different for virgin loading and unloading/reloading. In the Mohr Coulomb model, the limiting state of stresses is described by means of the friction angle, cohesion and dilatancy angle. However, in the Hardening Soil model, stiffness is described much more accurately by using three different stiffness types as input parameters: triaxial loading stiffness $\left(\mathrm{E}_{50}\right)$, triaxial unloading stiffness $\left(E_{u r}\right)$ and odometer loading stiffness ( $\left.E_{\text {oed }}\right)$. In most cases, $E_{u r}=3 E_{50}$ and $E_{\text {oed }}=E_{50}$ approximately (Jun Ju, 2013; Material Models Manual, 2015) and these values were adopted in this research study. Hence, $E_{\text {oed }}$ could be related to $E_{s}$ (Elastic Modulus) as given in Equation [1] [16, 18].
$E_{o \& d}=\frac{\left(1+v_{s}\right)\left(1-2 v_{s}\right)}{\left(1-v_{s}\right)} E_{s}$

Where, $\mathrm{v}_{\mathrm{s}}$ is the Poisson's ratio.

For the HS model, several other parameters such as Poisson's ratio in the case of loading and unloading $\left(\mathrm{V}_{\mathrm{ur}}\right)$, lateral earth pressure coefficient $\left(K_{0}=1-\sin \Phi\right)$, and failure ratio $\left(R_{f}\right)$ are also required as input parameters. The total strains for the HS model are calculated using a stress level dependent stiffness given by Equation [2] [12, 16, 18].

$E=E^{r e f}\left(\frac{c \cot \emptyset-\sigma_{1}^{\prime}}{c \cot \emptyset+p^{r e f}}\right)^{m}$

Where, $\mathrm{c}$ is cohesion, $\mathrm{m}$ is power in stiffness laws which can be defined between 0.5 and 1 $[12,16], \varphi$ is the angle of internal friction, $E_{\text {ref }}$ is the modulus at pref and $E_{s}$ is the modulus at $\sigma_{1}{ }^{1}$. It is suggested that a $v_{u r}$ of 0.2 and a $R_{f}$ of 0.9 are appropriate for the HS model under a drained condition [12]. The best parameters estimated for each layer of the HS model are summarized in Table 3.

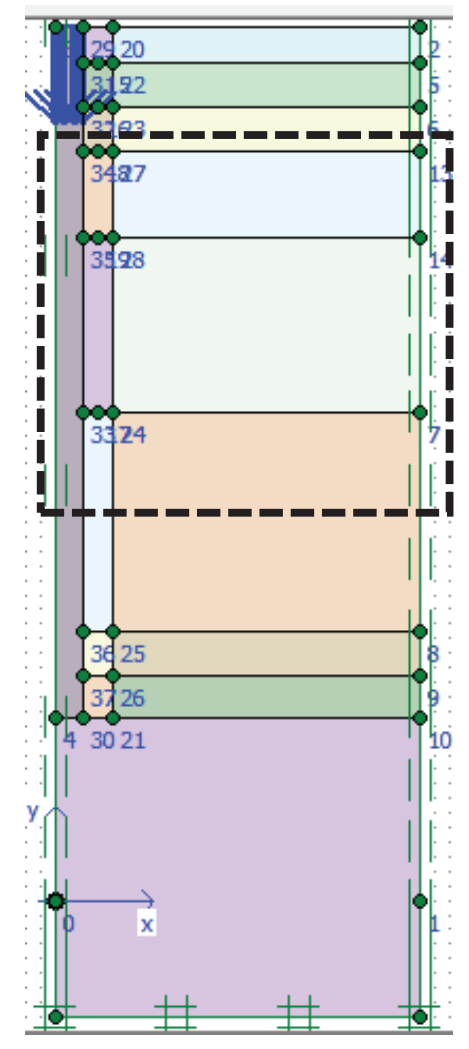

(a)

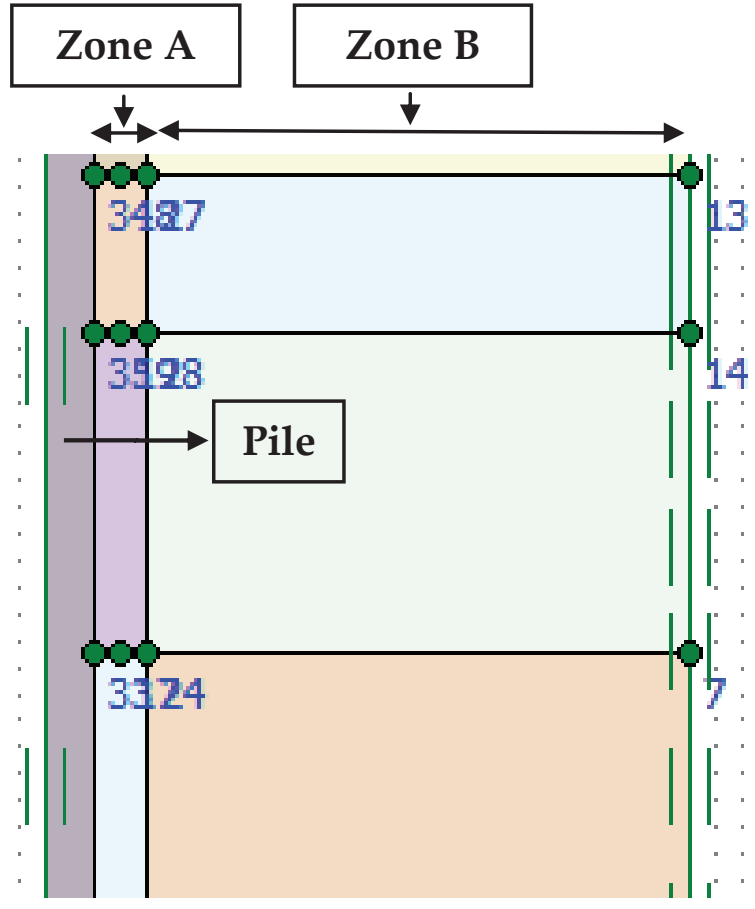

(b)

Figure 1 - (a) Geometry of NL-LE soil model and (b) Enlarged view of the highlighted region in (a) 


\section{FEM Analysis Methodology}

The numerical simulation of the single pile was performed using the finite element analysis in PLAXIS 2D. In this program, modelling was carried out under axisymmetric conditions with two degrees of freedom of translation per node. Soil was modelled by triangular elements with 15 nodes and with an elastoplastic behaviour obeying the Mohr-Coulomb failure criterion. The lateral sides of the computational domain were taken sufficiently away from the pile to avoid the boundary effect. All the models of the single pile used for different types of analysis have been made with a working area of $70 \mathrm{~m} \times$ $25 \mathrm{~m}$. All movements at the bottom of the model were restrained and any lateral movements perpendicular to the boundary were also restrained at the lateral sides.

A model made of linearly elastic, non-porous and isotropic material was used to represent the piles. Three different types of FE analyses were performed: (i) a Linear Elastic analysis (LE) where all the soil was assumed to be linearly elastic, (ii) a Complete Non Linear (CNL) analysis where soil adjacent to the pile shafts and between the piles (Zone A and Zone B) were modelled using the $\mathrm{HS}$ or the $\mathrm{MC}$ model, and (iii) a Non Linear and Linear analysis (NL-LE) where soil close to the pile shafts (Zone A in Figure 1) was modelled using the HS model, while soil in the remaining area (Zone B) was modelled considering it to be of LE or MC material. Three different sizes of Zone A were selected for the NL-LE analysis: (i) zone extended to a distance $d$ equal to one half of B from the pile shaft; (ii) $\mathrm{d}$ is equal to $\mathrm{B}$; and (iii) $\mathrm{d}$ is equal to $2 \mathrm{~B}$, where $\mathrm{B}$ is the pile diameter.

The size of the elements was to be as small as possible and close to the pile shaft (Zone A of Figure 1) because of the high stress gradient, which can capture a better pile behaviour. The element size could be larger near the boundaries on the condition that the distribution of stresses and settlements would not change very much when the size of the boundary elements was increased or decreased. The default interface and interface strength reduction factor $\left(\mathrm{R}_{\mathrm{int}}\right)$ was incorporated into the simulation and $R_{\text {int }}$ was taken as 0.85 [11]. The simulation sequence included an initial step in which the initial stress condition was established. Thereafter, the prescribed displacement was applied at the pile head and the variations of the applied load with the settlement were obtained. The computed results from all three types of models were compared with field test results in order to identify the model most suitable for the soil.

\subsection{Results and Discussion}

The load-settlement curve of the single pile was obtained using three types of FEM analyses, (i) Linear Elastic (LE) Analysis, (ii) Complete Non Linear (NL) Analysis and (iii) Non LinearLinear Elastic (NL-LE) analysis. Mohr Coulomb (MC) and Hardening Soil (HS) were the NL models considered in the settlement prediction of the single pile. The settlement behaviours predicted through the complete LE and NL analyses and their comparison with the measured load-settlement curve are shown in Figure 3.

According to the results, the measured settlement of the single pile was $3.5 \mathrm{~mm}$ at a typical working load of about 7, $000 \mathrm{kN}$. For the same working load, the settlement predicted from the HS model was $8.2 \mathrm{~mm}$ while that predicted from the MC model was more than twice the field measurement. Furthermore, the settlement values predicted from the Linear Elastic (LE) model and Mohr Coulomb (MC) model for the same working load are same and are equal to $6.8 \mathrm{~mm}$. Based on these observations, it can be stated that the settlement derived from LE and MC analyses is about 2 times higher than the field measurement obtained for a typical working load, and that there is a marked difference between the calculated and the measured curves of the single pile indicating that the calculation has over predicted significantly the pile head settlement or that it had underestimated the stiffness of soil.

There is a difference between the predicted and the measured values as the deep-in situ effect in the modulus has been disregarded. Actually, the modulus of deep soil obtained from laboratory tests significantly varies from its insitu value and at times the difference is several times [3]. The settlement of shallow foundations when tested under pressure using soil having a compression modulus between $100 \mathrm{kPa}$ and $200 \mathrm{kPa}$ will not generally have many errors. However, the settlement values calculated for soft soil of deep piles often differ very much from the measured values [3] as deep-insitu soil stiffness is always higher than that of samples used in the laboratories to obtain the elastic modulus. Therefore, Equation [3] proposed by Jian-lin et al. [3] was used in this study to predict the settlement more 
accurately. The elastic modulus obtained from laboratory tests were modified using Equation [3].

$$
E_{s, z}=E_{s, 0.1-0.2}\left(z / h_{0}\right)^{1 / \beta}
$$

where $\mathrm{z}$ is the depth of the soil layer $(\mathrm{m}), \mathrm{h}_{0}$ is the reference depth (generally $1 \mathrm{~m}$ ), $\mathrm{E}_{\mathrm{s}, 0.1-0.2}$ is the compression modulus obtained in the laboratory under a pressure of $100-200 \mathrm{kPa}$, and $\beta$ is the plasticity of the soil which can be obtained from the specifications given in the BS code, based on the liquid limit and plasticity index (IP) obtained from the data. For silty sand, $\beta$ would be between 3.5 and 5 [3].

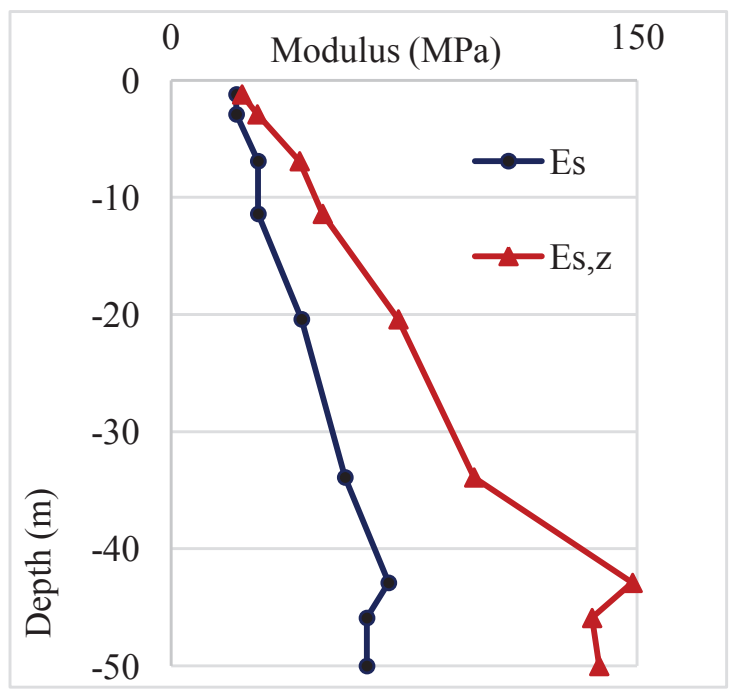

Figure 2 - Comparison between the experimental compression modulus $\left(E_{s}\right)$ and the corrected modulus $\left(\mathrm{E}_{\mathrm{s}, \mathrm{z}}\right)$
Finally, all three types of FE analyses were repeated using the corrected moduli $\left(\mathrm{E}_{\mathrm{s}, \mathrm{z}}\right)$ that were calculated using Equation [3] and the comparison of the values obtained for the modulus is shown in Figure 2. Again, the computed settlement results obtained using the three types of models were compared with the field test results.

In the next step, the FEM analysis was repeated with the corrected values of modulus in place of the values obtained from laboratory experiments, and the results obtained are shown in Figure 4. The settlement predicted from the complete HS model is $6.2 \mathrm{~mm}$ at a working load of $7,000 \mathrm{kN}$, while the settlement predicted from the Linear Elastic (LE) model and Mohr Coulomb (MC) model for the same working load are $4 \mathrm{~mm}$ and $3 \mathrm{~mm}$ respectively. The settlement values obtained using the corrected moduli are very much closer to the measured settlement value of $3.5 \mathrm{~mm}$. Even though the LE and MC models initially make better predictions than the HS model, they fail to present the real behaviour of the settlement and underestimate the settlement when the working load is increased beyond 13,000 $\mathrm{kN}$. The underestimated settlement of LE and MC may respectively have been because of the failure to consider soil nonlinearity and because of predicting the nonlinearity only approximately. On the other hand, the HS model due to its advanced nonlinearity, overestimates the settlement during the entire analysis.

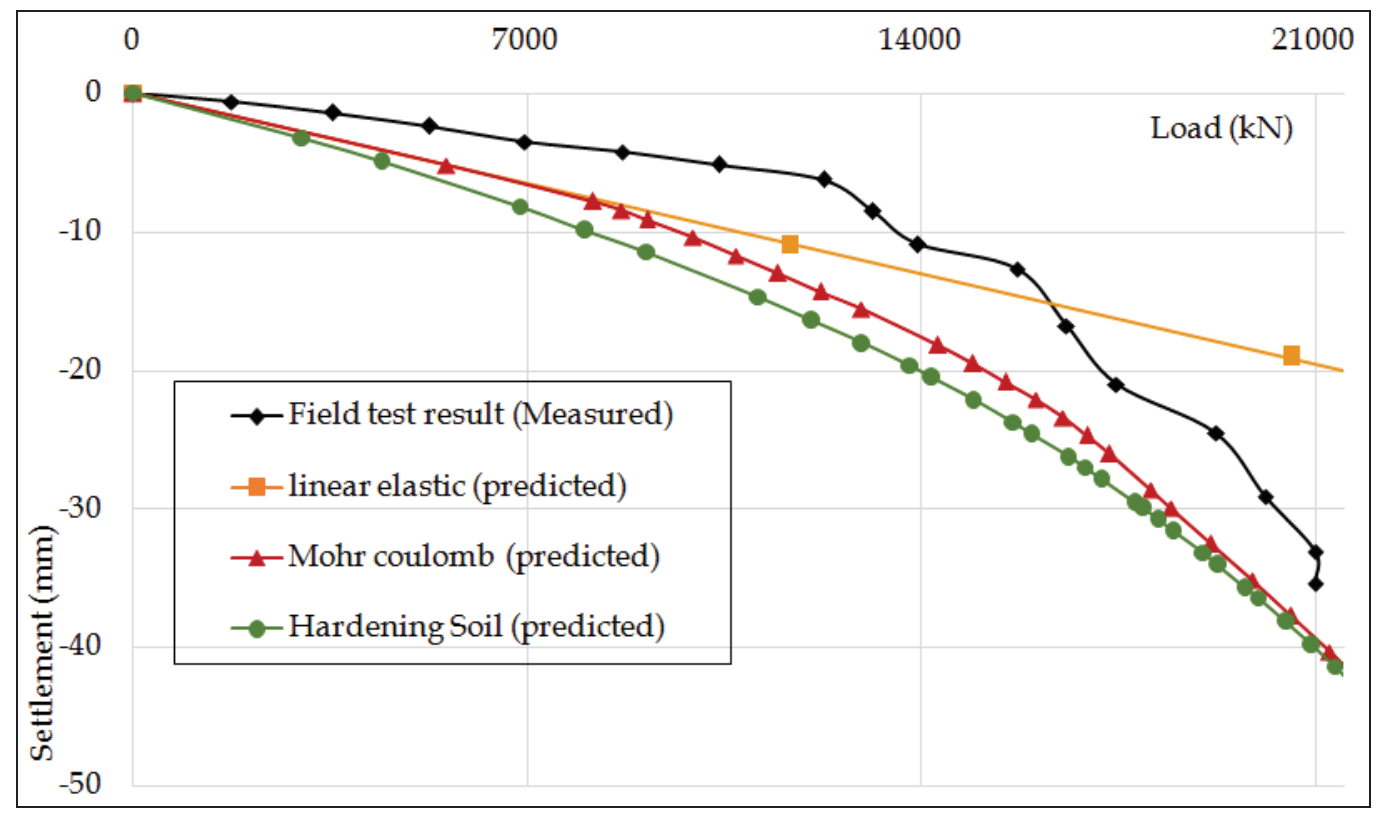

Figure 3 - Comparison between field test results and settlements predicted from LE and NL models 


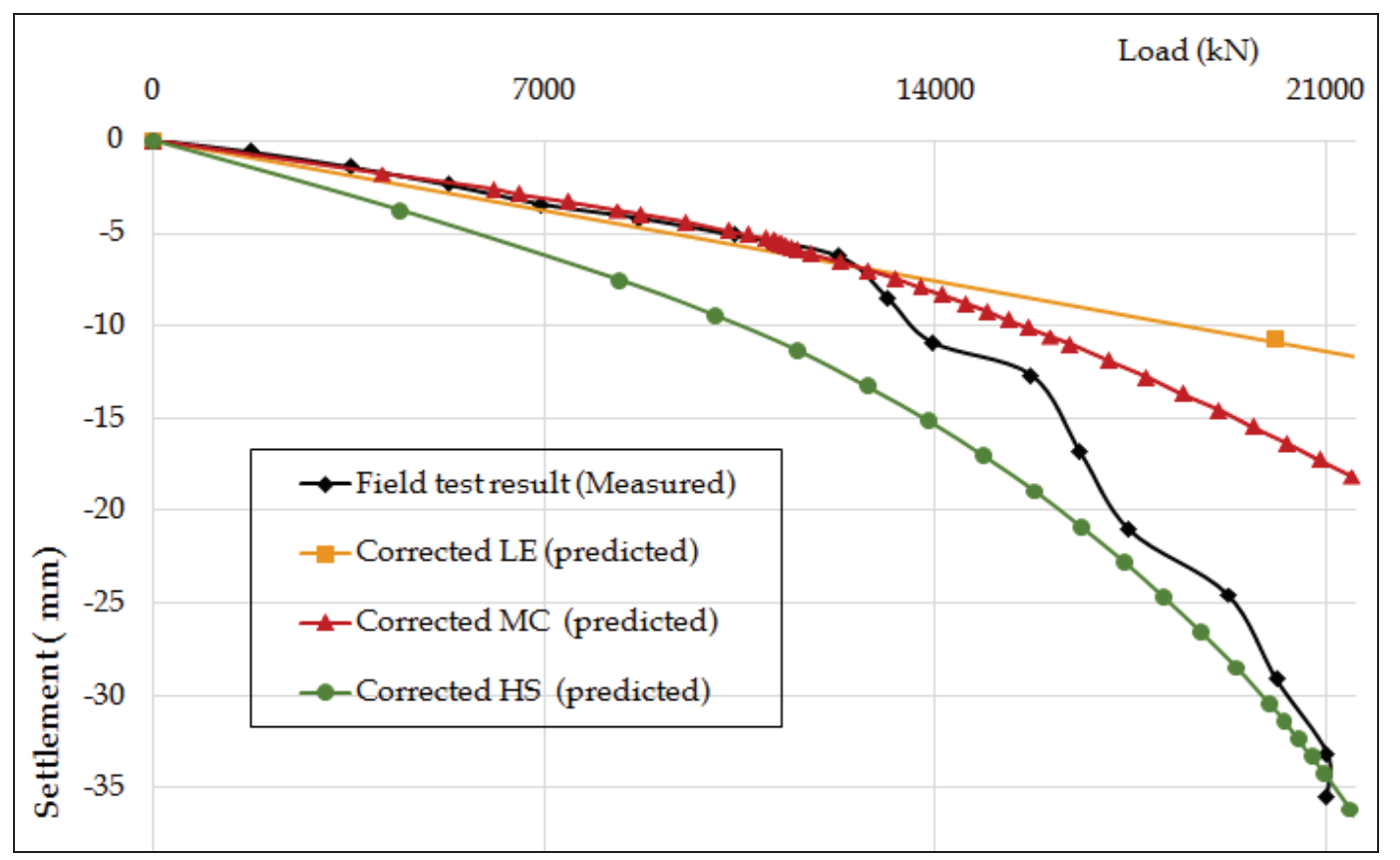

Figure 4 - Comparison between field test results and settlements predicted with the corrected modulus $\mathrm{E}_{\mathrm{s}, \mathrm{z}}$

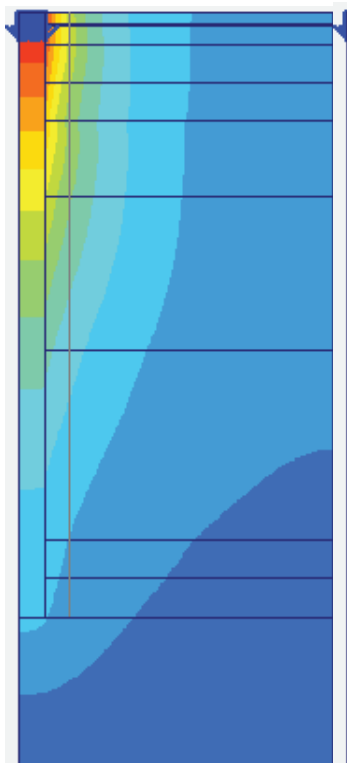

(a)

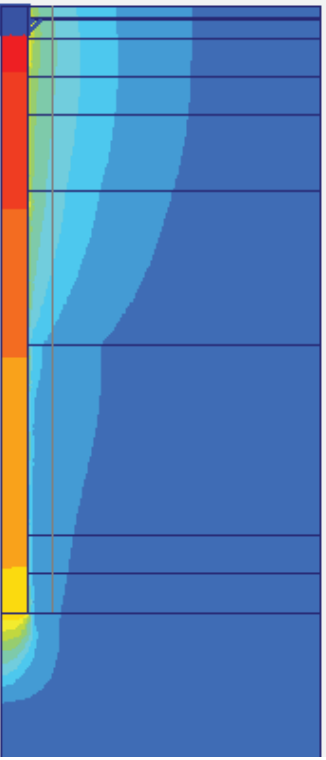

(b)

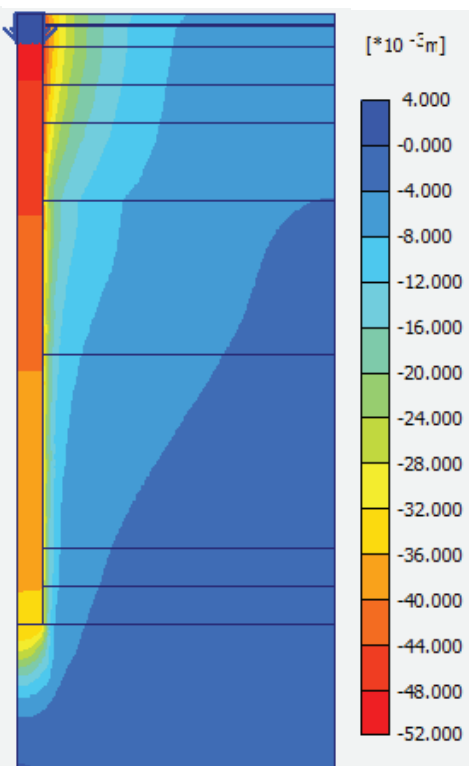

(c)

Figure 5 - Settlement contours of soil as (a) Complete LE model, (b) Complete MC model and (c) Complete HS model

An attempt was made to compare settlement contours for a settlement of $50 \mathrm{~mm}$ (allowable settlement) during all types of analysis, and the results obtained are presented in Figure 5. It can be seen that linear settlement contours appear when soil is modelled completely using the LE model (Figure 5-a) and this confirms the fact that the LE model disregards the nonlinearity of soil. When soil is modelled completely using the MC model (Figure 5-b), a few nonlinear contours are obtained in the settlement zone and this simple nonlinearity according to Zakia et al. [11], is adequate to predict the settlement behaviour at lower working loads up to about $13,000 \mathrm{KN}$, . [11]. On the other hand, when soil is completely modelled using the HS model (Figure 5-c), a large zone of settlement compared to that obtained from the MC model (Figure 5-b) appears showing clearly the advanced nonlinear contours. The complete HS model over predicts the settlement because of the increase in the stiffness reduction due to advanced nonlinearity. Therefore, it is very clear that by using a combination of Nonlinear and Linear (NL-LE) models and Nonlinear and simple Non Linear (NL-NL) models, it would 
be possible to predict realistically the behaviour of the settlement. The results obtained from the NL-LE analysis are presented in Figures 6 and 7. From Figure 6, it can be seen that NL-LE analysis using HS and LE models fail to provide an accurate prediction and the results appear to be related only to the average prediction. However, a combined analysis using HS and MC models provides a better prediction when the load is more than twice the working load. In this case in which a HS-MC model has been used, a HS zone of twice the diameter of the pile shaft as shown in Figure 7 with the remaining zone provided by the MC model, indicates better agreement with the field test result than any of the other models considered,. This combined analysis has already been suggested by Jun Ju [12] and Lee and Poulos [19].

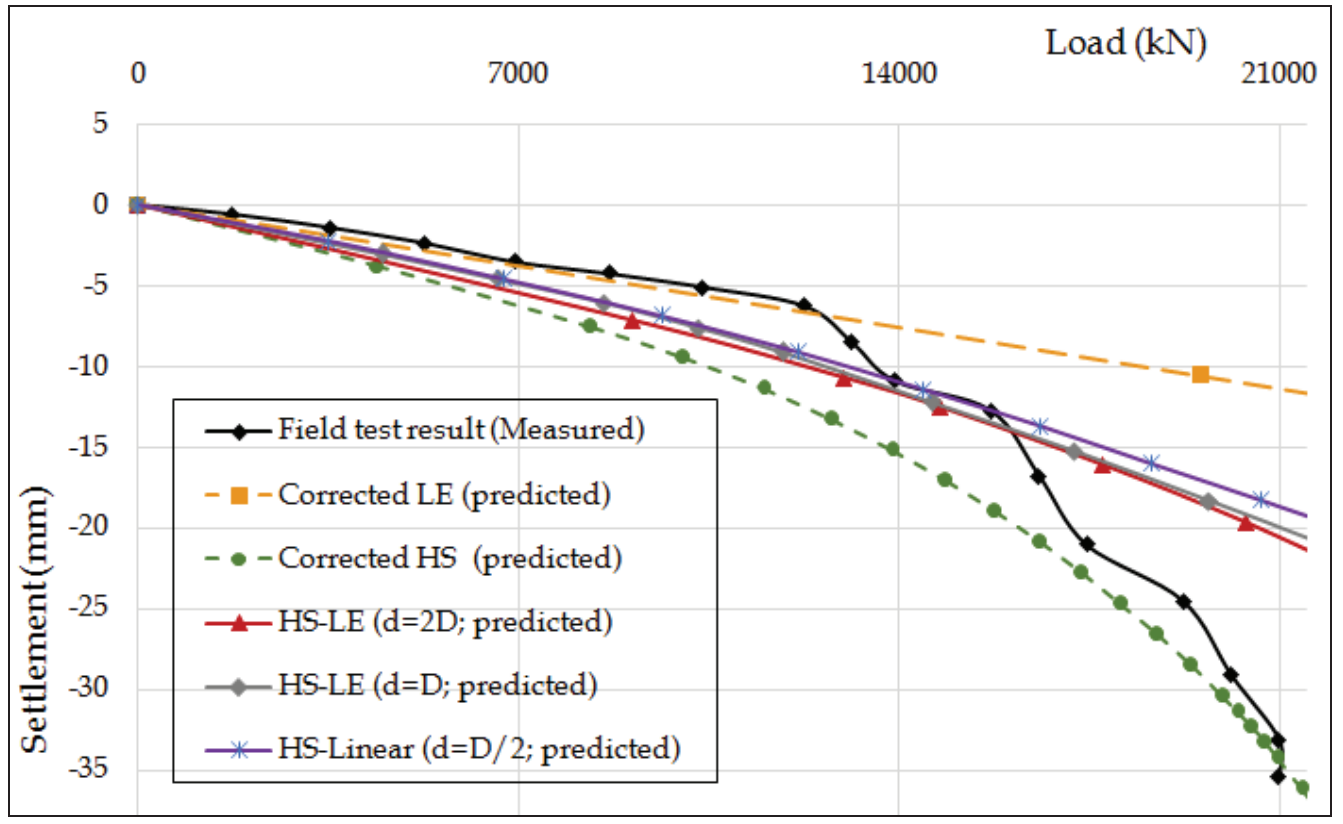

Figure 6 - Comparison between the measured and predicted load - settlement behaviour from NLLE (HS - LE) analysis.

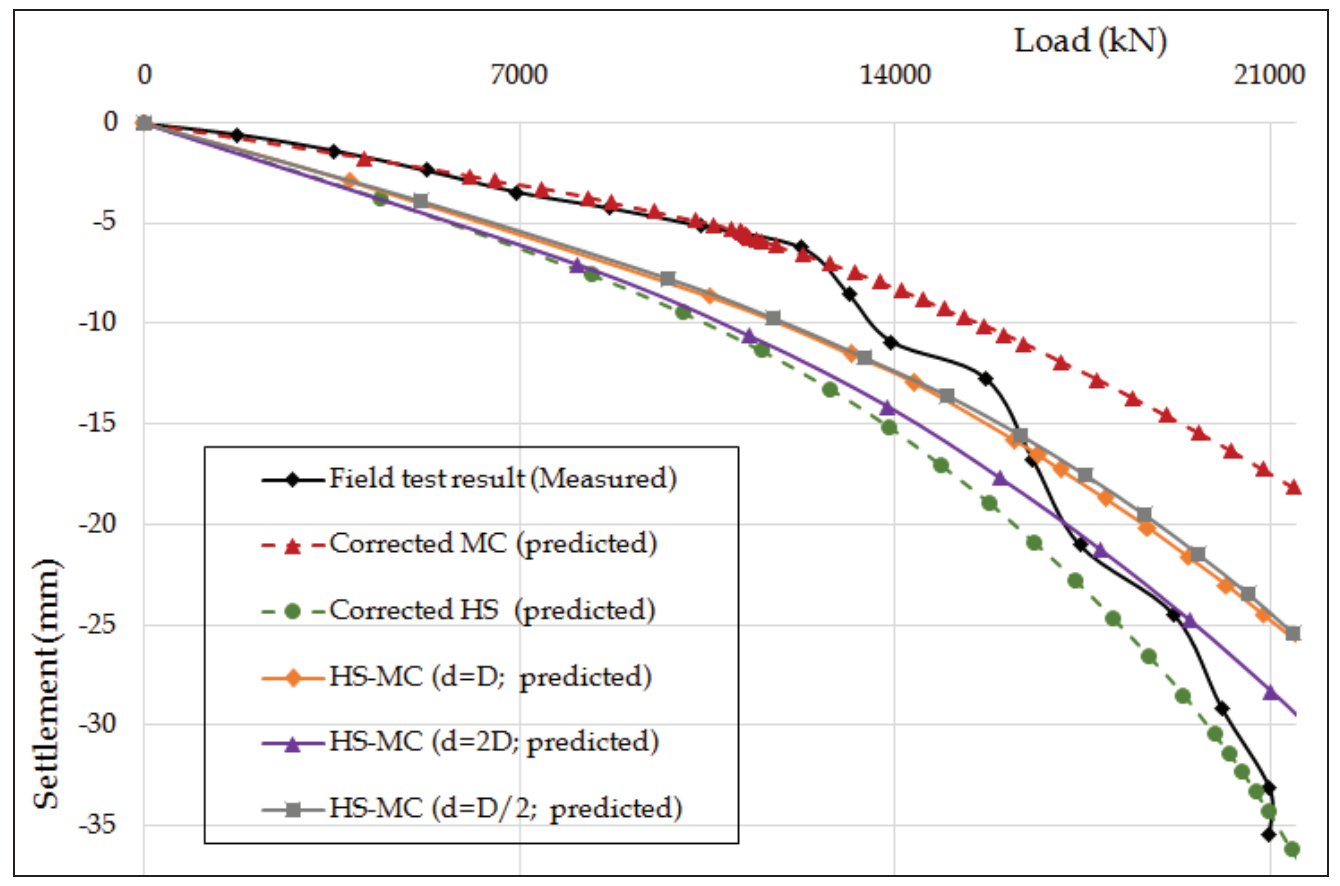

Figure 7 - Comparison between the measured and predicted load - settlement from NL-NL (HS MC) analysis 
Hence, it can be concluded that the corrected MC analysis agrees very well with observations up to a load of twice the working load and that at loadings beyond this value, the HS-MC analysis provides more realistic predictions of the settlement. The incorporation of an advanced nonlinear HS model at lower working loads appears to reduce the stiffness significantly, giving a better prediction of the settlement. As more soil elements reach the plastic state at higher working loads, the incorporation of the HS model with the MC model will provide the best fit with the observation.

\section{Conclusions}

A finite element study was conducted using PLAXIS 2D computer package to predict the settlement behaviour of piles. Analyses were conducted using different types of models based on the fact that soil has different types of material behaviour. The following conclusions can be drawn based on the outcomes of this research:

1. The modulus of a soil mass will decrease as the strain level is increased and the strain level may increase as the pile shaft is approached.

2. When a single model has to be used for the entire interface, the Mohr Coulomb (MC) model will be the best model to predict the settlement of a single pile and its simple nonlinearity will be adequate to predict realistically the settlement at lower working loads up to about $13,000 \mathrm{kN}$.

3. A single nonlinear (NL) model and a combination of a nonlinear - linear elastic (NL-LE) analysis with a nonlinear zone of soil around the pile with linearly elastic soil beyond that zone will give better predictions of the settlement compared to a pure NL model.

4. Out of the two combined models used [NL - LE (HS - LE) and NL - NL (HS - MC)], the combination of a NL - NL model and a HS - MC model would provide a better prediction for loads above $15,000 \mathrm{kN}$.

5. On the whole, when numerical simulations are done to predict settlements realistically, the understanding and the selection of the proper material model is very important. Material model selection will not only depend on the characteristics of soil, but will also depend on the type and loading conditions of the structure (will not depend on the magnitude of the load, but on the value of the loading, i.e., whether it is above the working/design load or not).

\section{Acknowledgements}

We would like to thank the Department of Civil Engineering, University of Peradeniya for giving us the opportunity to conduct this research.

\section{References}

1. Reed, L. M., "Load-Transfer Criteria for Numerical Analysis of Axially Loaded Piles in Sand", Technical report of U. S. Army Engineer Division, Part 1, 1984.

2. Cao, M., Chen, Z., \& Chen, S. I., “An Innovative Approach to Evaluate the Behaviour of Vertically Loaded Pile Groups Based on Elastic Theory", Lowland Technology International vol. 9, no. 1, 2007, pp. 1-10.

3. Jian-lin, Aziz, H. Y., \& SUChun-hui, SHI Cong., "Settlement Prediction and Behavior of Pile Foundations in Deep Clayey Soil Deposits", Central South University Press and Springer-Verlag Berlin Heidelberg, Vol. 21, 2014, pp. 1554-1564.

4. McCabe, B. A., \& Lehane, B. M., "Behaviour of Axially Loaded Pile Groups Driven in Clayey Silt", Journal of Geotechnical and Environmental Engineering, 2006, pp. 401-410.

5. Horikoshi, K., Matsumoto, T., Hashizume, Y., \& Watanabe, T., "Performance of Piled Raft Foundations Subjected to Dynamic Loading", International Journal of Physical Modelling in Geotechnics, 2003, Vol. 3 (2), pp. 51-62.

6. Poulos, H. G., "Analysis of the Settlement of Pile Groups", Geotechnical Journal, No. 4, 1968, pp. 449-471.

7. Sonia, A., \& Desai, C. S., "Load-Deformation Response of Axially Loaded Piles", Journal of Geotechnical Engineering, Vol. 113(12), 1987, pp. 1483-1500.

8. Randolph, M. F., \& Wroth, C. P., “Analysis and Deformation of Vertically Loaded Piles", Geotechnical Engineering, ASCE, 104(GT12), 1978, pp. 1465-1487.

9. Randolph, M. F., "Load Transfer Analysis of Axially Loaded Piles", RATZ manual version 4.2, University of Western Australia, 2003. 
10. XUE Fu-chun, MA Jian-lin, \& YAN Li-ping., "Three-Dimensional FEM Analysis of Bridge Pile Group Settlement in Soft Soils", Geotechnical Special Publication, No. 220, ASCE, 2011, pp. 135-143.

11. Zakia, K., Abdelmadjid, B., \& Nazihe, T., "Modelling the Behaviour of Axially Loaded and Laterally Loaded Pile with a Contact Model", EJGE Bund, vol.16, 2011, pp. 1239-1257.

12. Jun, Ju., "Prediction of the Settlement for the Vertically Loaded Pile Group Using 3D Finite Element Analyses", Marine Geo-resources \& Geotechnology, Vol. 33:3, 2013, pp. 264-271.

13. Alnuiam, A., El Naggar H., \& El Naggar, M. H., "Performance of Piled-Raft System under Axial Load", 18th International Conference on Soil Mechanics and Geotechnical Engineering, 2013, pp. 2663-2666.

14. Orihara, K., \& Khoo, K. S., "Engineering Properties of Old Alluvium in Singapore and its Parameters for Bored Pile and Excavation Design", Thirteenth Southeast Asian Geotechnical Conference, 1998, pp. 545-550.

15. Li, Sharma, Chu \& Zhao., "Geological and Geotechnical Features of Singapore: An Overview", Tunnelling and Underground Space Technology, Vol.15, No.4, 1991, pp.419 - 431.

16. "PLAXIS", Material Models Manual, 2015.

17. Schanz, T., \& Vermeer, P. A., "The HardeningSoil Model: Formulation and Verification", In Proceedings of the Plaxis Symposium, Beyond 2000 in Computational Geotechnics. Brinkgreve, R. B. J. Rotterdam: Balkema, 1999, pp. 281- 290.

18. Sadrekarimi, J., \& Akbarzad, M., “Comparative Study of Methods of Determination of Coefficient of Subgrade Reaction", International Technology, vol. 14, 2009, pp. 1-14.

19. Lee, C. Y. \& Poulos, H. G., "Axial Response Analysis of Piles in Vertically and Horizontally Non-Homogeneous Soils", Computers and Geotechnics, Vol. 9, 1990, pp. 133-148. 